\title{
Reply to the letter
}

\section{Francisco Fuentes-Ocampo $^{1}$ (D) • D. A. López-Mora ${ }^{1} \cdot$ A. Flotats $^{1} \cdot$ I. Carrió $^{1}$}

Received: 11 April 2019 / Accepted: 22 April 2019 / Published online: 7 May 2019

(C) Springer-Verlag GmbH Germany, part of Springer Nature 2019

\section{Dear Sir,}

We thank Koopman et al. for their comments and interest in our recent article [1, 2]. It is well known that various technical and physics issues, such as detector performance, voxel size and reconstruction parameters, influence SUV measurements [3, 4].

The aim of our study was not to evaluate the influence of such factors on SUV measurements, but to compare under true clinical conditions the values produced by a digital scanner with those produced by an analogue scanner. The patients were scanned on the same day following a single injection of radiotracer in one imaging session with a digital scanner and with an analogue scanner installed next to each other in our department. The acquisition and reconstruction parameters selected for the digital and analogue PET/CT scans were those known to produce the best image quality under clinical conditions [2] and to provide the best lesion detectability [5]. Furthermore, with the analogue scanner, the voxel size could not be modified.

In coming years, digital PET/CT systems will be deployed worldwide and will coexist with traditional analogue scanners. Differences in clinical performance will guide the selection of the appropriate system for a given indication. We believe that the information derived from our study, with regard to differences in SUVs in the same patients and lesions between those produced by a digital and by an analogue system, is relevant for

Francisco Fuentes-Ocampo

ffuenteso@santpau.cat

1 Nuclear Medicine Department, Hospital de la Santa Creu I Sant Pau, Autonomous University of Barcelona, Pare Claret 167,

08025 Barcelona, Spain the selection of the appropriate scanner in patients who need to undergo follow-up studies to assess the effect of treatments over time.

\section{Compliance with ethical standards}

\section{Conflicts of interest None.}

Ethical approval This article does not contain any studies with human participants or animals performed by any of the authors.

\section{References}

1. Koopman D, Jager PL, van Dalen JA. Small-voxel reconstructions significantly influence SUVs in PET imaging. Eur J Nucl Med Mol Imaging. 2019. https://doi.org/10.1007/ s00259-019-04301-y.

2. Fuentes-Ocampo F, López-Mora DA, Flotats A, Paillahueque G, Camacho V, Duch J, et al. Digital vs. analog PET/CT: intra-subject comparison of the SUVmax in target lesions and reference regions. Eur J Nucl Med Mol Imaging. 2019;46(5):1204. https://doi.org/10. 1007/s00259-019-04280-0.

3. Koopman D, van Dalen JA, Lagerweij MC, Arkies H, de Boer J, Oostdijk $\mathrm{AH}$, et al. Improving the detection of small lesions using a state-of-the-art time-of-flight PET/CT system and small-voxel reconstructions. J Nucl Med Technol. 2015;43(1):21-7. https://doi.org/10. 2967/jnmt.114.147215.

4. Koopman D, van Dalen JA, Arkies H, Oostdijk AH, Francken $\mathrm{AB}$, Bart J, et al. Diagnostic implications of a small-voxel reconstruction for loco-regional lymph node characterization in breast cancer patients using FDG-PET/CT. EJNMMI Res. 2018;8:3. https://doi.org/10.1186/s13550-018-0359-7.

5. López-Mora DA, Flotats A, Fuentes-Ocampo F, Camacho V, Fernández A, Ruiz A, et al. Comparison of image quality and lesion detection between digital and analog PET/CT. Eur J Nucl Med Mol Imaging. 2019. https://doi.org/10.1007/ s00259-019-4260-z.

Publisher's note Springer Nature remains neutral with regard to jurisdictional claims in published maps and institutional affiliations. 